\title{
Isolated olfactory cleft involvement in SARS-CoV-2 infection: prevalence and clinical correlates
}

\author{
Chiara Spoldi ${ }^{1}$ - Luca Castellani ${ }^{1}$ - Carlotta Pipolo ${ }^{1}$ (1) $\cdot$ Alberto Maccari $^{1} \cdot$ Paolo Lozza $^{1} \cdot$ Alberto Scotti $^{1}$. \\ Antonia Pisani ${ }^{1}$. Giuseppe De Donato ${ }^{1}$. Sara Portaleone ${ }^{1} \cdot$ Maurizio Cariati ${ }^{2}\left[{ }^{\circ}\right.$. Giovanni Felisati ${ }^{1} \mathbb{0}$. \\ Alberto Maria Saibene ${ }^{1}$ (I)
}

Received: 30 April 2020 / Accepted: 20 June 2020 / Published online: 23 June 2020

(c) Springer-Verlag GmbH Germany, part of Springer Nature 2020

\begin{abstract}
Purpose Smell alterations are a symptom of COVID-19 and have been associated with olfactory cleft mucosal thickening (OCMT). Although their pathogenesis is unclear, evidences link them to viral neuroinvasive potential. This study aims at estimating the prevalence of OCMT in CT scans of COVID-19 patients and investigating its clinical correlates.

Methods In a single-institution retrospective cross-sectional study, we included all patients hospitalized for COVID-19 undergoing head CT scan for any reason. Exclusion criteria were history of recent head trauma or chronic rhinosinusitis; opacification $>2 \mathrm{~mm}$ in any sinonasal space other than the olfactory cleft; CT performed during/after invasive ventilation or feeding via nasogastric tube. We recorded the prevalence of OCMT and related it to age, sex, need for invasive ventilation during hospital stay, outcome, length of hospital stay, diffusion of lung SARS-CoV-19 lesions and outcome.

Results 63 eligible patients were identified (39 male, 24 female; median age $77.82 \pm 17.77$ years). OCMT was identified in 16 patients (25.4\%; 95\% CI 15.3-37.9\%). Patients with OCMT had longer hospital stays (median $16 \pm 4$ vs. $9 \pm 14.5$ days, $\mathrm{p}=.009$, Mann-Whitney $U$ test) and required invasive ventilation more frequently than patients without mucosal thickening (OR 4.89, 95\% CI 0.96-24.89, $p=.063$, Fisher's test). No other difference was observed.

Conclusion OCMT affects nearly one in four patients hospitalized for COVID-19. It is associated with a worse disease course irrespective of age, sex and diffusion of lung lesions, although with no direct effect on survival.
\end{abstract}

Keywords Olfaction disorders $\cdot$ Smell $\cdot$ Coronavirus $\cdot$ Mucous membrane $\cdot$ Viral tropism

\section{Abbreviations \\ OC Olfactory cleft \\ CT Computed tomography}

Spoldi Chiara and Castellani Luca contributed equally to this study.

Alberto Maria Saibene

alberto.saibene@gmail.com

1 Otolaryngology Unit, ASST Santi Paolo e Carlo, Department of Health Sciences, Università Degli Studi di Milano, Milan, Italy

2 Radiology and Interventional Radiology Unit, ASST Santi Paolo e Carlo, Department of Health Sciences, Università Degli Studi di Milano, Milan, Italy

\section{Introduction}

While many viral infections are known to affect the olfactory system and even use its neural connections to reach the central nervous system [1], smell disturbances induced by SARS-CoV-2 infection recently exploded into a media sensation [2].

Sudden, often isolated, hyposmia is a known symptom of COVID-19 [3, 4], and some authors suggested it might be due to selective olfactory cleft (OC) obstruction, blocking odorant molecules from reaching their receptors [5].

While the actual mechanisms controlling smell disturbances in COVID-19 are unclear, several evidences link it to the direct neuroinvasive potential of SARS-CoV-2 [6-8], which might involve the olfactory pathways and reach the brainstem, with a potential detrimental role on patients' ventilation [6].

Smell alterations in COVID-19 patients have been covered by several original studies, but OC involvement 
has been evaluated only in a single case report [5] and at present, no information is available on its prevalence and clinical significance.

To shed some light on this matter, we conducted a retrospective study aimed at estimating the radiologic prevalence of isolated OC involvement in COVID-19 patients and investigating its clinical correlates.

\section{Materials and methods}

The study was designed as a retrospective cross-sectional study.

We reviewed charts and radiological studies from all patients admitted to a tertiary care teaching hospital in Lombardy, Italy, from March 1st, 2020, for SARS-CoV-2 infection (last search April 23rd), identifying patients who underwent head computed tomography (CT) for any clinical reason during the hospital stay.

Exclusion criteria were

- history of head trauma during the hospital stay or in the 30 days preceding hospital admission;

- history of chronic rhinosinusitis;

- opacification $>2 \mathrm{~mm}$ in any sinonasal space other than the olfactory cleft in the CT;

- CT performed during or after invasive ventilation or during or after feeding with nasogastric tube.

Head CT scans from eligible patients were reviewed blindly by two authors (CP and PL) for OC mucosal thickening, defined as isolated, complete, opacification of the cleft, not coupled to any other mucosal thickening in the sinonasal cavities.

All patients underwent at least a chest radiograph or CT scan during the hospital stay. Radiologic images and respective radiology reports were reviewed blindly by two authors (MC and AS) for SARS-CoV-2-relatable groundglass opacities with or without consolidation (as reported by Zhou et al. [9]). Opacities diffusion was rated 0 (no lesions) to 3 (lesions in the lower, middle and upper lobes) for each lung, for a total score ranging from 0 to 6 .

Patients' charts were reviewed and the following data were collected for each patient: age at admission; sex; need for invasive ventilation; outcome (still hospitalized, died of disease or complications, recovered); and total hospital stay.

All disagreements between raters were solved by consensus.

CT and chart data were collected into a Google Spreadsheet (Google LLC, Mountain View, CA, US), anonymized and extracted.
We performed descriptive statistics and statistical analysis on the collected data to compare data between patients with and without OC opacification (Fig. 1).

Analysed variables were age at admission (Mann-Whitney $U$ test), sex distribution (Fisher test), need for invasive ventilation during hospital stay (Fisher test), final outcome (Fisher test), length of hospital stay (Mann-Whitney $U$ test) and diffusion of lung lesions (Mann-Whitney $U$ test). All tests were performed on the whole study population, with the exception of final outcome (for which patients who were still hospitalized at time of last chart search were excluded) and hospital stay length (which was considered only in recovered patients).

All statistical analyses were performed using the IBM SPSS Statistics for Windows software, Version 25.0 (IBM Corporation, Armonk, NY, US). Tests were two tailed and values of $p<0.05$ were considered to indicate statistical significance.

\section{Results}

Among a pool of 786 COVID-19 patients admitted in our hospital, 70 patients underwent a head CT scan during the hospital stay. These patients had a CT scan performed as a first-line evaluation for possible nonspecific neurological symptoms (dizziness, vertigo, headache). None of them underwent a CT scan for sinonasal sort of problems. According to our inclusion and exclusion criteria, seven of them were excluded for opacification $>2 \mathrm{~mm}$ in sinonasal

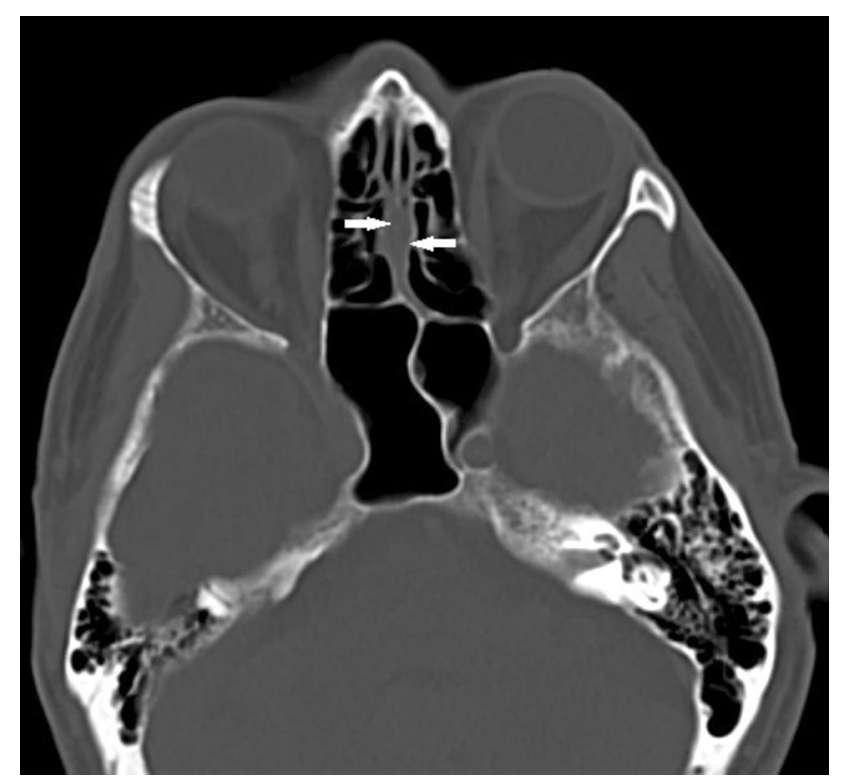

Fig. 1 Plain axial CT image showing bilateral mucosal thickening of the olfactory cleft (white arrows). No sorts of mucosal changes are visible in the image, as for the remainder of the CT scan 
spaces other than the OC (among these patients, two were also under invasive ventilation at time of CT scan, two had history of unspecified sinonasal problems, and one of them had a nasogastric feeding tube). No patient was excluded for chronic sinusitis or trauma history alone

We, therefore, identified 63 eligible patients ( 39 male, 24 female; median age $77.82 \pm 17.77$ years, range $43-95$ years). Isolated OC opacification was identified in 16 patients (25.4\%; 95\% CI 15.3-37.9\%). Among these, nine patients had a unilateral OC opacification, while the remaining seven had a bilateral OC opacification. 47 patients were free from any kind of sinonasal opacification $(74.6 \%$; $95 \%$ CI $62.1-84.7 \%$ ).

Data concerning all analysed variables, along with the statistical test used and its significance are reported in Table 1.

Only two variables showed a significantly different distribution among the two study groups. First, Mann-Whitney $U$ test showed that patients with OC opacification had significantly longer hospital stays ( $16 \pm 4$ vs. $9 \pm 14.5$ days, $p=0.009)$. Second, patients with OC opacification required invasive ventilation more frequently $33.33 \%$ of OC patients (95\% CI 7.3-52.4\%) vs. of non-OC patients $(95 \%$ CI 1.3-17.5\%); OR 4.89, 95\% CI 0.96-24.89, $p=0.063$, Fisher's test).

\section{Discussion}

This is the first literature article focusing on the prevalence and clinical significance of OC involvement in COVID-19 patients. First and foremost, our data show that OC mucosal thickening affects about one in four patients requiring hospitalization for SARS-CoV-2 infection. Second, our data seem to suggest that this finding may be associated in selected populations with a worse disease course irrespectively of age, sex and diffusion of lung lesions, although at present there seems to be no direct effect on survival.

Although we are at present unable to provide any pathophysiological hypothesis to this findings, they seem indeed far from simple coincidences and might confirm both the viral tropism for the central nervous system and, in turn, its role in respiratory failure in COVID-19 patients [6]. In this regard, smell dysfunction could be just one of the several neurological manifestations of the disease [10], albeit the only one that could be easily identified in basic radiological studies through OC mucosal thickening. Furthermore, OC opacifications more closely related to clinical outcomes than simple hyposmia, which is not related to disease severity in preliminary studies [11].

Since other Coronavirus epidemics such as SARS and MERS showed no peculiar impact on olfactory function, we have no prior disease models. Only post-mortem identification of SARS-CoV-2 in the central nervous system and, in particular, in the olfactory mucosa could allow us to verify viral spread into neural tissues. Nevertheless, a selective involvement of the OC may explain also the temporary

Table 1 Study variables in the study group and in the two subpopulations

\begin{tabular}{|c|c|c|c|c|c|}
\hline & & Whole study group & $\begin{array}{l}\text { Patients without OC } \\
\text { involvement }\end{array}$ & $\begin{array}{l}\text { Patients with OC } \\
\text { involvement }\end{array}$ & $\begin{array}{l}\text { Statistical test and } \\
\text { significance }\end{array}$ \\
\hline \multicolumn{2}{|l|}{ Number of patients } & 63 & $\begin{array}{l}47(7.6 \% ; 95 \% \mathrm{CI} \\
62.1-84.7 \%)\end{array}$ & $\begin{array}{l}16(25.4 \%, 95 \% \mathrm{CI} \\
15.3-37.9 \%)\end{array}$ & N/A \\
\hline \multicolumn{2}{|l|}{ Age (years) } & $77.82 \pm 17.77(43-95)$ & $77.82 \pm 16.65(45-95)$ & $74.74 \pm 21.01(43-89)$ & $\begin{array}{l}\text { Mann-Whitney } U \text { test, } \\
p=.368\end{array}$ \\
\hline \multirow[t]{2}{*}{ Sex (no. $(\%))$} & Male & $39(61.90 \%)$ & $30(63.82 \%)$ & $9(56,25 \%)$ & \multirow[t]{2}{*}{ Fisher test, $p=.766$} \\
\hline & Female & $24(38.09 \%)$ & $17(36.17 \%)$ & $7(43,75 \%)$ & \\
\hline \multirow{2}{*}{$\begin{array}{l}\text { Invasive ventilation } \\
\text { during hospital stay } \\
\text { (no. }(\%))\end{array}$} & Yes & $7(11.11 \%)$ & $3(6.38 \%)$ & $4(25 \%)$ & \multirow[t]{2}{*}{ Fisher test, $p=.061$} \\
\hline & No & $56(88.8 \%)$ & $44(93.61 \%)$ & $12(75 \%)$ & \\
\hline \multirow[t]{3}{*}{$\begin{array}{l}\text { Final outcome (no. } \\
(\%) \text { ) }\end{array}$} & $\begin{array}{l}\text { Still hospital- } \\
\text { ized }\end{array}$ & $28(44.44 \%)$ & $22(46.08 \%)$ & $6(37.50 \%)$ & \multirow{3}{*}{$\begin{array}{l}\text { Fisher test, } p=.227 \\
\text { comparing only } \\
\text { deceased or recov- } \\
\text { ered patients }\end{array}$} \\
\hline & Deceased & $24(17.46 \%)$ & $19(40.42 \%)$ & $5(31.25 \%)$ & \\
\hline & Recovered & $11(17.46 \%)$ & $6(12.76 \%)$ & $5(31.25 \%)$ & \\
\hline \multicolumn{2}{|c|}{$\begin{array}{l}\text { Hospital stay for recovered patients in the } \\
\text { group (days) }\end{array}$} & $12 \pm 8.5(4-24)$ & $9 \pm 14.5(1-44)$ & $16 \pm 4(12-24)$ & $\begin{array}{l}\text { Mann-Whitney } U \text { test, } \\
p=.009\end{array}$ \\
\hline \multicolumn{2}{|c|}{ Lung lesion diffusion (score) } & $3 \pm 3(0-6)$ & $3 \pm 3(0-6)$ & $3 \pm 2.25(1-6)$ & $\begin{array}{l}\text { Mann-Whitney } U \text { test, } \\
p=.773\end{array}$ \\
\hline
\end{tabular}

$O C$ olfactory cleft 
nature of anosmia in these patients, who might recover after infection thanks to ectomesenchymal stem cells contained in the olfactory mucosa, way more accustomed to infectious insults than the central nervous system [12].

It has to be noted that this study has several limitations that have to be taken into account besides its retrospective design. The study has been conducted only on patients requiring hospital admission for varying degrees of respiratory failure; thus, it has a significant bias towards selecting worse COVID-19 patients, which are, therefore, not representative of the general infected populations. Thus, our observations could relate only to a more vulnerable subset of patients. Furthermore, our observation being based only on retrospective traceable data, we are at present unable to link OC mucosal thickening with smell alterations in these patients.

Nevertheless, we think that novelty and strength of information conveyed by the study surpass the limitation of its design, and should spur other researchers to explore the role of OC obstruction in SARS-CoV-2 infection. We suggest indeed to attentively inspect the olfactory cleft in any head CT scan performed in COVID-19 patients, no matter the clinical indication.

\section{Compliance with ethical standards}

Conflict of interest The authors declare that they have no conflict of interest.

Research involving human participants and/or animals All procedures performed in studies involving human participants were in accordance with the ethical standards of the institutional research committee and with the 1964 Helsinki Declaration and its later amendments or comparable ethical standards.

Informed consent Informed consent for clinical procedures was already obtained from all individual participants included in the study.
2. Walker A, Hopkins C, Surda P (2020) The use of google trends to investigate the loss of smell related searches during COVID19 outbreak. Int Forum Allergy Rhinol. https://doi.org/10.1002/ alr.22580

3. Lechien JR, Chiesa-Estomba CM, De Siati DR, Horoi M, Le Bon SD, Rodriguez A et al (2020) Olfactory and gustatory dysfunctions as a clinical presentation of mild-to-moderate forms of the coronavirus disease (COVID-19): a multicenter European study. Eur Arch Otorhinolaryngol. https://doi.org/10.1007/s00405-02005965-1

4. Wee LE, Chan YFZ, Teo NWY, Cherng BPZ, Thien SY, Wong $\mathrm{HM}$ et al (2020) The role of self-reported olfactory and gustatory dysfunction as a screening criterion for suspected COVID-19. Eur Arch Otorhinolaryngol. https://doi.org/10.1007/s00405-02005999-5

5. Eliezer M, Hautefort C, Hamel A-L, Verillaud B, Herman P, Houdart E et al (2020) Sudden and Complete Olfactory Loss Function as a Possible Symptom of COVID-19. JAMA Otolaryngol Head Neck Surg. https://doi.org/10.1001/jamaoto.2020.0832

6. Li Y-C, Bai W-Z, Hashikawa T (2020) The neuroinvasive potential of SARS-CoV2 may play a role in the respiratory failure of COVID-19 patients. J Med Virol. https://doi.org/10.1002/ jmv. 25728

7. Toscano G, Palmerini F, Ravaglia S, Ruiz L, Invernizzi P, Cuzzoni MG et al (2020) Guillain-Barré syndrome associated with SARSCoV-2. N Engl J Med. https://doi.org/10.1056/NEJMc2009191

8. Marinosci A, Landis BN, Calmy A (2020) Possible link between anosmia and COVID-19: sniffing out the truth. Eur Arch Otorhinolaryngol. https://doi.org/10.1007/s00405-020-05966-0

9. Zhou Z, Guo D, Li C, Fang Z, Chen L, Yang R et al (2020) Coronavirus disease 2019: initial chest CT findings. Eur Radiol. https ://doi.org/10.1007/s00330-020-06816-7

10. Asadi-Pooya AA, Simani L (2020) Central nervous system manifestations of COVID-19: a systematic review. J Neurol Sci 413:116832

11. Moein ST, Hashemian SMR, Mansourafshar B, Khorram-Tousi A, Tabarsi P, Doty RL (2020) Smell dysfunction: a biomarker for COVID-19. Int Forum Allergy Rhinol. https://doi.org/10.1002/ alr.22587

12. Tanos T, Saibene AM, Pipolo C, Battaglia P, Felisati G, Rubio A (2017) Isolation of putative stem cells present in human adult olfactory mucosa. PLoS ONE 12:e181151

Publisher's Note Springer Nature remains neutral with regard to jurisdictional claims in published maps and institutional affiliations.

\section{References}

1. Soler ZM, Patel ZM, Turner JH, Holbrook EH (2020) A primer on viral-associated olfactory loss in the era of COVID-19. Int Forum Allergy Rhinol. https://doi.org/10.1002/alr.22578 